\title{
The effects of Phonetic Variables on the Devoicing of Initial Stops in spoken Egyptian Arabic
}

\section{Dr. Rawhia Ahmed and Amal Kandeel}

Department of Phonetic and Linguistic

Sciences, Faculty of Arts

University of Alexandria. 


\section{Introduction:}

The present study investigates the effect of place, emphasis, stress and different vocalic context on devoicing in initial stops in Colloquial Egyptian Arabic (CEA). Voicing is considered a major developmental problem. Among the other phonological processes, devoicing is considered one of the most frequent processes occurring in the speech of Egyptian children (Ammar. 1992; Ammar \& Morsi. 2006; Ammar \& Rifaat. 2004; Elmoataz-Bellah. 2008; Morsi. 2001; Salameh et al. 2003). In stops production, it can be defined as "the absence or cessation of vocal-fold vibration during the closure phase of stop" (Temple. 2000: p.193).

The literature on voicing acquisition support Jakobson's proposed universal that "so long as stops in child language are not split according to the behavior of the glottis, they are generally produced as voiceless and unaspirated" (Macken \& Ferguson. 1987: p.13) Kewley-Port \& Preston (1974) correlate this to the ease of articulation. Voiceless unaspirated stops are easier to control than either prevoiced or aspirated stops. The literature on CEA was concerned with the phonologies 
of both phonologically disordered and normal Egyptian children. Ammar (1992) investigated the phonologies of both normal and phonologically disordered Egyptian children. The subjects of her study were divided into two groups; normal children group and phonologically disordered group. The normal group consisted of sixteen children, aged between four years one month and four years ten months. The subjects of the disordered group were sixteen, aged between four years one month to nine years two months.

Ammar \& Morsi (2006) investigated the phonological system of Egyptian children speech. The subjects of her study were 36 children. They were divided into two groups according to their age. Group I consisted of 10 children aged between three and four year olds. Group II consisted of 26 children aged between four and five year olds. Ammar \& Rifaat (2004) investigated the phonemic and the phonetic inventories and the phonological processes of normal Egyptian children. They also proposed clinical implications of the results. The subjects of their study were 20 monolingual normally developing children. They aged between 24 to 30 months. 
Elmoataz-Bellah (2008) described the phonological development of forty Egyptian children aged between one to three years and divided into two groups, group one included stage I and II aged one to two years and group two included stage III and IV aged two to three years.

Morsi (2001) described the phonological development of normal Egyptian children and proposed some implications for designing a developmental articulation test for phonologically disordered children. The subjects of her study were divided into three stages according to their ages. Each stage contains five males and five females. The children's age of stage I were ranged from two years and six months to three year olds. Stage II were ranged from three to four year olds. Stage III were ranged from four to five year olds. The results of all previous studies on CEA showed that devoicing was one of the most common processes in children speech.

\section{Method}

\subsection{Subjects:}

The subjects of the present study are 10 normaldeveloping Egyptian children for both age-group three 
and five (five subjects for each age-group). All the subjects were chosen to exhibit no prominent regionalism in their speech in order to control the dialectal variations as much as possible.

\subsection{Speech material:}

The tested materials were chosen to represent the dental, velar stops and its emphatic counterparts /d, $\underline{\mathbf{d}}$, $\mathrm{g}, \mathrm{g} /{ }^{1}$ initially in both stressed and unstressed syllables with different qualities and lengths of vowels. The subjects repeated the tested words after Egyptian Arabic speaker in the sentence frame "/------kelma sahla/" (-

2.3 Recording and analysis:

The speech materials were recorded on a high quality tape (Sony zx type I or TDK B type I) in a quiet room by using a unidirectional dynamic microphone and a Radioshack tape recorder. Auditory analysis was made for each token to determine whether the tested sounds were heard as voiced or voiceless. These judgments were made by the researchers.

${ }^{1}$ The /d/ are considered as phoneme in ECA while, /g/ are considered as allophone. 


\section{Results and discussions}

Table (1) presents the percentage of devoicing as a function of: place of articulation, emphasis effect, stress effect, vowel length effect, and vowel height effect for both age-groups three and five.

\begin{tabular}{|c|c|c|c|}
\hline \multicolumn{2}{|c|}{ The tested variable } & Three & Five \\
\hline \multirow{2}{*}{ Place } & Dental & $\mathbf{3 0}$ & $\mathbf{1 1}$ \\
\cline { 2 - 4 } & Velar & 38 & $\mathbf{6}$ \\
\hline \hline \multirow{2}{*}{ Emphasis } & Plain & $\mathbf{3 4}$ & $\mathbf{1 3}$ \\
\cline { 2 - 4 } & Emphatic & 33 & $\mathbf{4}$ \\
\hline \multirow{2}{*}{ Stress } & Stressed & 36 & $\mathbf{1 0}$ \\
\cline { 2 - 4 } & Unstressed & $\mathbf{3 2}$ & $\mathbf{6}$ \\
\hline \multirow{2}{*}{ Vowel length } & Short & 36 & $\mathbf{1 0}$ \\
\cline { 2 - 4 } & Long & $\mathbf{3 1}$ & $\mathbf{1 0}$ \\
\hline \hline \multirow{3}{*}{ Vowel height } & Low & $\mathbf{2 7}$ & $\mathbf{9}$ \\
\cline { 2 - 4 } & Mid & 34 & 11 \\
\cline { 2 - 4 } & High & 31 & $\mathbf{3 1}$ \\
\hline
\end{tabular}

Table (1): The percentage of devoicing as a function of different variables.

The results showed that the percentage of devoicing decreased as age increased. It registered a higher average percentage for age group three (34\%) than age-group five (9\%). The present study showed that for the age-group of three, it appears that all phonetic variables influence devoicing of phonologically voiced stops with the exception of emphasis. However, in age-group five only place, emphasis and stress affect devoicing. 
In general, the influence of the different phonetic variables on the devoicing of phonologically voiced stops comes from age-group three rather than agegroup five. We do not have a satisfactory explanation for this tendency except that the overall percentage of devoicing in age-group five is small when compared with that in age-group three. Therefore, any influence of the different phonetic variables is more obvious in age-group three rather than age-group five.

Concerning the place effect, in age-group three devoicing was observed more frequently for velar stops (38\%) than for dental ones $(30 \%)$. For example, the word /gunu:n/ devoiced more frequently compared with /duru:s/. Pape et al (2003) found the same results in their investigation of German stops initially in adults. Explanation for this is purely aerodynamic. Since the cavity behind the point of constriction of the velar stop has a smaller volume than that behind the dental one, then supraglottal pressure during stop closure will build up more rapidly in velar stop and cessation of voicing is thus more likely to occur. For age-group five, the opposite trend was observed unlike what is expected the dental stop (11\%) is more often subject to devoicing than the velar one $(6 \%)$. This finding suggests that the 
aerodynamic explanation does not hold true in all cases and that therefore some variations of devoicing pattern are attributed to speaker control (i.e., represents learned behavior rather than automatic behavior).

Concerning the emphasis effect, Figure(3) presents the percentage of devoicing occurrence as a function of emphasis effect for both age-groups three and five. The results showed that the emphasis has a significant effect on devoicing of initial stops only in age-group five while, it does not affect age-group three. For age-group three, the percentage of devoicing in plain stops is $34 \%$ and the percentage in emphatic ones is $33 \%$. This may be due to the fact that younger children tend to deemphasize the emphatic stops. Unlike what is predicted from the aerodynamic explanation of devoicing occurrence, the results showed that in age-group five devoicing was observed more frequently for plain stops (13\%) than for the emphatic ones (4\%). For example, the word /dab $\Phi /$ devoiced more frequently compared with /darb/. From the aerodynamic explanation of devoicing occurrence we can predict that emphasis stop is more often subject to devoicing than its plain counterparts. As emphasis stops are slightly retracted compared to its plain counterpart (Harrell. 1957), there 
is a smaller volume of air behind the point of constriction compared to Plain stops. Therefore, supraglottal pressure during stop closure will build up more rapidly in the emphatic stop and cessation of voicing is thus more likely to occur.

In the case of stress effect, unlike the other variables we found agreement between both age-group three and age-group five. Figure (4) presents the percentage of devoicing occurrence as a function of stress effect for both age-groups three and five. The results showed that stops in stressed syllables are more often subject to devoicing than stops in unstressed syllables. For example, the word /gunna/ devoiced more frequently compared with /gunu:n/. In the case of agegroup three, the percentage of devoicing in stressed syllables is $36 \%$ and the percentage in unstressed ones is $32 \%$. In the case of age-group five, the percentage of devoicing in stressed syllables is $10 \%$ and the percentage in unstressed ones is $6 \%$.

Regarding vowel length effect, we found that in age-group three stops before short vowels $(36 \%)$ are more often subject to devoicing than stops before long vowels $(31 \%)$. For example, the word /dab $\Phi$ / devoiced more frequently compared with /da:b/. However, in 
age-group five the effect of vowel length is insignificant. In this case, the percentages of devoicing before both short and long vowels are $10 \%$. Figure (5) shows the percentage of initial stops devoicing occurrence as a function of vowel length effect for both age-groups three and five.

Concerning the vowel height effect, The results showed that the effect of vowel height is only significant in age-group three. In this age-group stops that are followed by low vowels are more resistant to devoicing than stops before both mid and high vowels. For example, the word /da:b / devoiced less frequently compared with /di:n/ and /de:n/. There is no difference between both the percentage of devoicing before mid and high vowels. The percentage of devoicing before low vowels is $27 \%$, is $\mathbf{3 4 \%}$ before mid vowels and is $31 \%$ before high vowels. However in age-group five, there is no significant difference between the percentage of devoicing before low, mid and high vowels. The percentage of devoicing before low vowels is $9 \%$, the percentage before mid vowel one is $8 \%$, and the percentage before high vowels is $11 \%$. Pape et al (2003) found that contrary to our results, the stop was more often devoiced when followed by the mid and low 
vowels compared to the high vowels. They attributed this tendency to the enlarged pharyngeal cavity for high vowels. This explanation does not hold true in our data.

\section{Conclusions}

1. The percentage of devoicing decreased as age increased.

2. The influence of the different phonetic variable on devoicing pattern was more obtained at age-group three rather than age-group five. This might be because the overall percentage of age-group five was small compared to that of age-group three.

3.In age-group three the devoicing pattern is affected by the place of articulation, presence or absence of stress and the different vocalic contexts. Stops are more resistant to devoicing in dental position, in unstressed syllables and before both low and long vowels.

4. In age-group five place, emphasis and stress affect devoicing. Stops are more resistant to devoicing in velars, emphatics and unstressed syllables. 


\section{References}

Ammar, W. (1992). Articulation disorders in Arabic-Speaking Children. Ph.D. dissertation, University of Alexandria.

Ammar, W. \& Morsi, R. (2006). "Phonological development and disorders: Colloquial Egyptian Arabic". In Zhu, Hua and B.Dodd (eds.). Phonological development and disorders, Vol.IX, Pp.204-232.

Ammar, W. \& Rifaat, Kh. (2004). "The Phonological Acquisition of Colloquial Egyptian Arabic by 24- to 30-month Normal Egyptian Children". Child Language Seminar, Bristol, UK.

Elmoataz-Bellah, M. (2008). Early phonological acquisition of Arabic of one to three years Egyptian children. MA. Thesis, university of Alexandria.

Harrel, R.S. (1957). The phonology of colloquial Egyptian Arabic. New York: American Council of Learned Societies.

Kewley-Port, D., \& M.S. Preston. (1974). "Early apical stop production: a voice onset time analysis". Journal of Phonetics, Vol.II, Pp.195-210. 
Macken, M.A. \& Ferguson, CH.A. (1987). "Phonological universals in language acquisition". Interlanguage phonology: the acquisition of a second language sound system, Ioup, G. \& Heinberger, S.H. (Ed.), NewBury housepublishers, Cambridge, Pp.3-22

Morsi, R. (2001). Developmental articulation test for phonologically disordered Egyptian children. Unpublished MA thesis, University of Alexandria.

Pape, D. \& Mooshammer, Ch. \& Hoole, Ph. \& Fuchs, S. (2003). " Devoicing of word-initial stops: a consequence of the following vowel?". Proceedings of the 6th International Seminar on Speech Production, Sydney.

Salameh, E-K. \& Nettelbladt, U. \& Norlin, K. (2003). " Assessing phonologies in bilingual SwedishArabic children with and without language impairment". Child Language Teaching and Therapy, Vol. XIX, Number 3, Pp. 338-364.

Temple, R.A.M. (2000). "Now and then: The evolution of Male-Female differences in the voicing of consonants in two varieties of French". Leeds working papers in linguistics, Nelson, D. \& Foulkes, P. (Eds.), Vol.VIII, Pp.193-204. 
Appendix (A)

Speech Samples 
1. /dab $\Phi$ /

2. /dirs/

3. /dubna/

4. /da:b/

5. /di:n/

6. /de:n/

7. /du:b/

8. /do:b/

9. /da $9 a: l i /$

10. /diwa:ni/

11. /duru:s/

12. /darb/

13. /dilim/

14. /duraf/

15. /da:f/

16. /dii:?/

17. /de:f/

18. /du:r/

19. /d do: ?/

20. /dali: 9 a/

21. /dila:l/

22. /d dulu: ؟/

23. /gabha/

24. /gibna/
25. /gunna/

26. /ga:f/

27. /gi:b/

28. /ge:b/

29. /gu:!/

30. /go:n/

31. /gama:l/

32. /gibi:ra/

33. /gunu:n/

34. /garru/

35. /gurn/

36. /ga:r/

37. /go:ra/

38. /garso:n/

39. /gira:h/

40. /gurna:n/ 


\section{Appendix (B)}

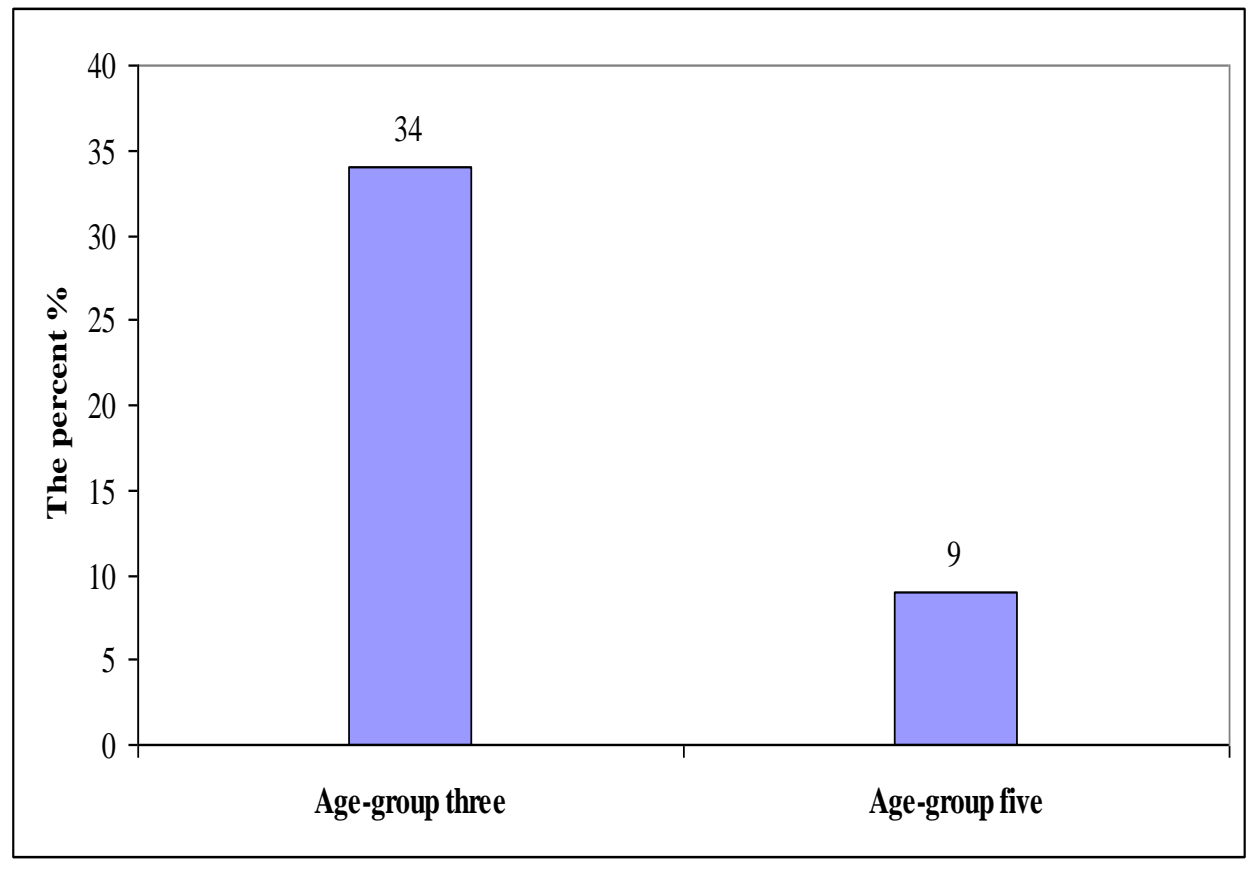

Figure (1): The percentage of devoicing as a function of different age-groups. 


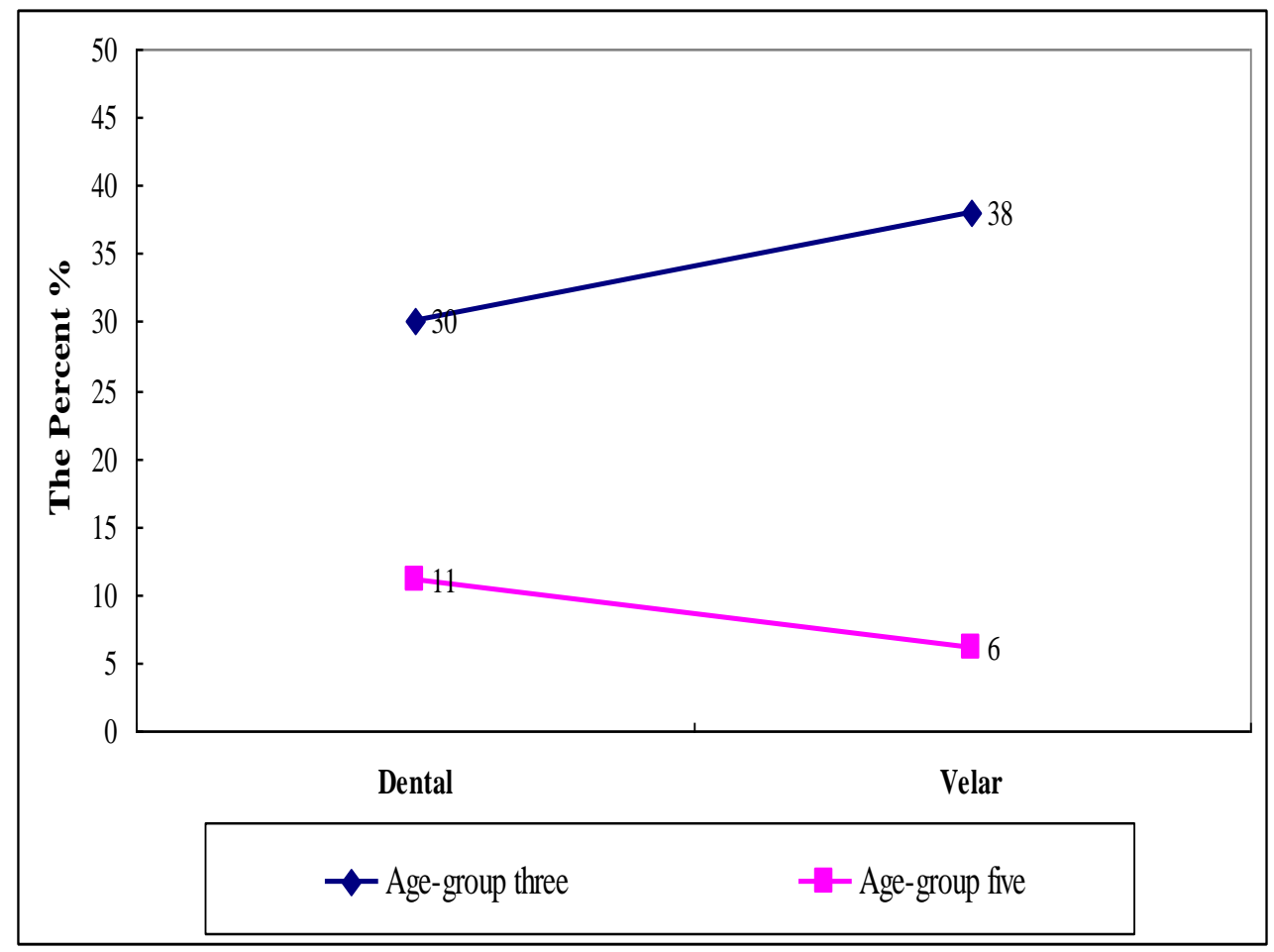

Figure (2): The percentage of devoicing as a function of different place. 


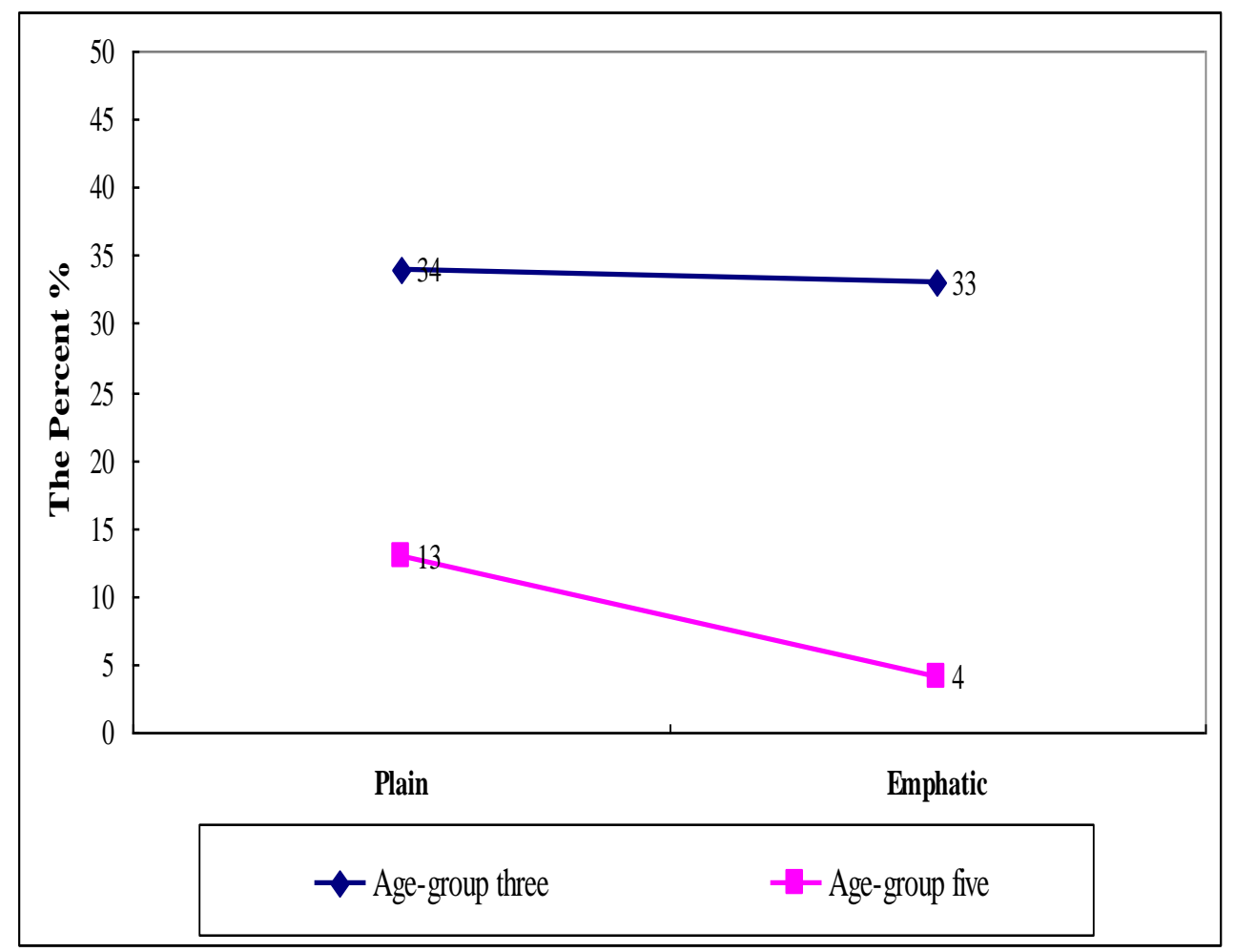

Figure (3): The percentage of devoicing as a function of emphasis effect. 


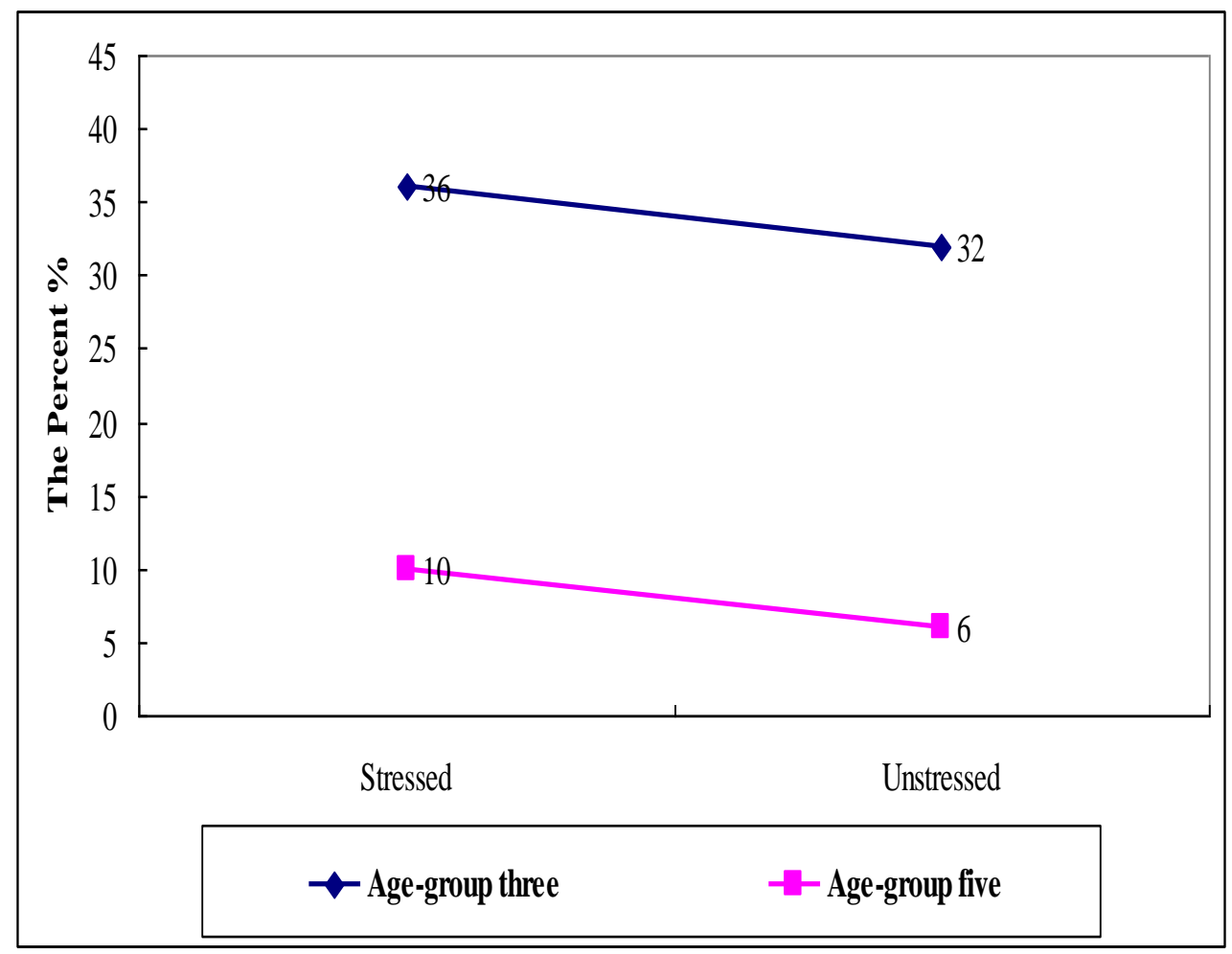

Figure (4): The percentage of devoicing as a function of stress effect. 


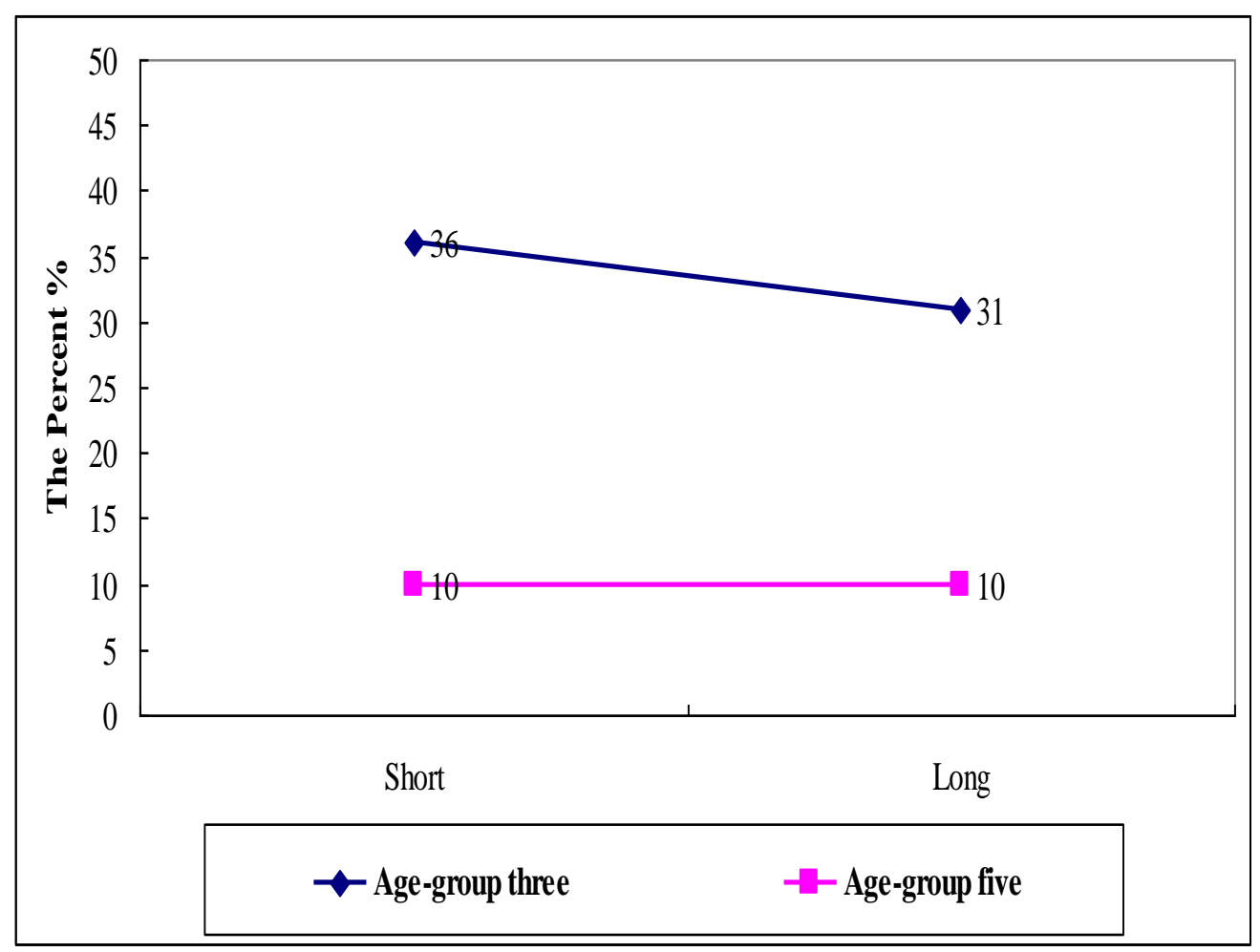

Figure (5): The percentage of devoicing as a function of vowel length effect. 


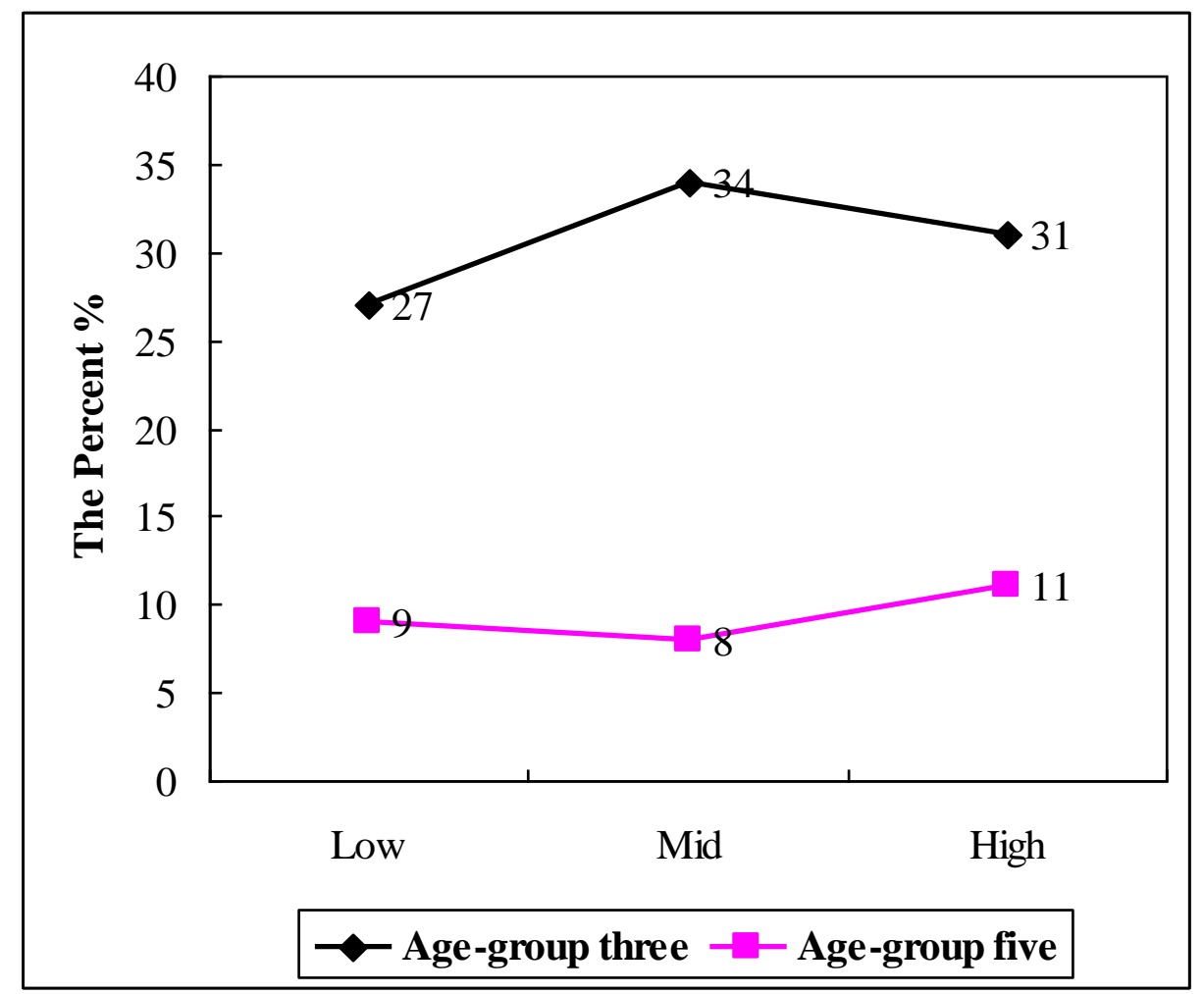

Figure (6): The percentage of devoicing as a function of vowel height effect. 